\title{
Outdoor Operation of Small-Molecule Organic Photovoltaics
}

\section{Quinn Burlingame, ${ }^{a}$ Gloria Zanotti, ${ }^{b, 1}$ Laura Ciammaruchi, ${ }^{b, 2}$ Eugene A. Katz,${ }^{b, c}$ and Stephen R. Forrest ${ }^{a, d, e, *}$}

a) Department of Electrical Engineering and Computer Science, University of Michigan, Ann Arbor, MI 48109,USA

b) Department of Solar Energy and Environmental Physics, J. Blaustein Institutes for Desert Research, Ben-Gurion University of the Negev, Sede Boqer Campus, 84990, Israel

c) Ilse Katz. Inst. of Nano-Science and Technology, Ben-Gurion University of the Negev, Be'er Sheva 84105, Israel

d) Department of Materials Science and Engineering, University of Michigan, Ann Arbor, MI 48109, USA

e) Department of Physics, University of Michigan, Ann Arbor, MI 48109, USA

1) Present address: CNR - Instituto di Struttura della Materia Via Salaria km 29,500 00015 , Monterotondo Scalo (Rm), Italy

2) Present address: ICFO - Institut de Ciències Fotòniques, Parc Mediterani de la Technologia, 08860 Castelldefels (Barcelona), Spain

* Corresponding author. Telephone: 1-734-647-1147; Fax: 1-734-763-0085; Email: stevefor@umich.edu

\begin{abstract}
We measure the diurnal dependence of the operating characteristics of tetraphenyldibenzoperiflanthene (DBP): $\mathrm{C}_{70}$ planar-mixed heterojunction small-molecule organic photovoltaic (OPV) cells with 2,2',2”-(1,3,5-benzenitryl tris-[1-phenyl-1H-benzimidazole] (TPBi): $\mathrm{C}_{70}$ electron-filtering cathode buffer layers. Over the course of a day, efficiency gradually increases as a result of a concomitant increase in short-circuit current, while the fill factor and
\end{abstract}


open-circuit voltage remain constant. The results are analyzed on the basis of independent measurements of temperature- and intensity-dependent OPV performance. The power conversion efficiency is maximized slightly below 1 sun intensity and at $40^{\circ} \mathrm{C}$, which is beneficial for practical outdoor operation. We attribute the increased short circuit current with temperature to broadening of the absorption spectrum due to population of phonon states along with increased charge mobility, which also results in an increase in fill factor. 


\section{Introduction}

Significant progress in the development of efficient and stable organic photovoltaics (OPV) is opening the possibility for their large-scale deployment. ${ }^{1-5}$ Outdoors, power conversion efficiency $(P C E)$ and output power generated by photovoltaic cells depend on environmental factors such as irradiance, spectrum of the incident sunlight, and temperature. Therefore, the dependence of $P C E$ on these factors, and in particular its diurnal dependence provides information for the practical application of OPVs for the solar generation of electricity. Diurnal behavior has been studied for inorganic photovoltaics, ${ }^{6,7}$ while such information for polymer OPVs is limited, ${ }^{8,9}$ and completely absent for small molecule OPVs.

The temperature and light intensity dependence of OPVs are determined by, among other factors, bimolecular recombination, exciton dissociation, carrier mobility, optical absorption, and resistive power losses. ${ }^{8,10-14}$ Variations in intensity and temperature, therefore, are frequently used to characterize organic materials and devices. ${ }^{12,15-18}$ Here we report an analysis of the diurnal, temperature, and light intensity dependent performance of small molecular-weight planar-mixed heterojunction $(\mathrm{HJ})$ OPVs based on tetraphenyldibenzoperiflanthene (DBP): $\mathrm{C}_{70}$ photoactive layers, with stable 2,2',2"-(1,3,5-benzenitryl tris-[1-phenyl-1H-benzimidazole] $(\mathrm{TPBi}): \mathrm{C}_{70}$ electron-filtering compound buffer layers. Planar-mixed HJ DBP:C $\mathrm{C}_{70}$ devices are among the most stable OPV cells demonstrated to date, with lifetimes of $T_{80}>2500 \mathrm{hr}$ measured under laboratory conditions, and no degradation after 100 days of outdoor testing. ${ }^{5,19}$ Here, $T_{80}$ is the time it takes for the PCE to decrease to $80 \%$ of its initial value. The cells have been found to be stable under intense solar irradiation and high temperature, making them suitable for further investigations under realistic operating conditions..$^{5}$. We find that power conversion efficiency is maximized slightly below 1 sun intensity and at $40^{\circ} \mathrm{C}$, which is beneficial for practical outdoor 
operation. We attribute the increased short circuit current observed with increasing temperature to broadening of the absorption spectrum due to thermal population of phonon states along with increased charge mobility, which also results in a concomitant marginal increase in fill factor.

\section{Experimental}

The materials $\mathrm{Al}, \mathrm{MoO}_{\mathrm{x}}, \mathrm{C}_{70}, \mathrm{DBP}$, and tris-[1-phenyl-1H-benzimidazole] (TPBi) used in the OPV cells were obtained from commercial sources, and all organic molecules were purified prior to use by thermal gradient sublimation in vacuum. ${ }^{20}$ The devices were grown on prepatterned indium tin oxide (ITO)-coated glass substrates that were sonicated in a tergitol/deionised (DI) water solution followed by sonication in DI water, acetone, and isopropyl alcohol. Substrates were dried in a stream of ultrahigh purity $\mathrm{N}_{2}$ and placed on a hot plate at $100^{\circ} \mathrm{C}$ for cleaning with a stream of $\mathrm{CO}_{2}$ gas for $1 \mathrm{~min}$, followed by a $10 \mathrm{~min}$ exposure to ultraviolet (UV)-ozone. ${ }^{21}$

Devices were grown by thermal evaporation under high vacuum $\left(<2 \times 10^{-7}\right.$ torr $)$ at deposition rates between 0.2 and $1.6 \AA / \mathrm{s}$, with the structure: $150 \mathrm{~nm}$ ITO/10nm MoO $/ 54 \mathrm{~nm} 1: 8$ DBP:C ${ }_{70} / 9 \mathrm{~nm} \mathrm{C}_{70} / 10 \mathrm{~nm}$ 1:1 TPBi:C $\mathrm{C}_{70} / 3 \mathrm{~nm}$ TPBi/100nm Al. The intersection of a shadow-maskpatterned $\mathrm{Al}$ cathode and the ITO anode defined an $11.3 \mathrm{~mm}^{2}$ device area. Devices were encapsulated in an ultrahigh purity $\mathrm{N}_{2}$-filled glovebox $\left(<1\right.$ ppm $\mathrm{O}_{2}$ and $\left.\mathrm{H}_{2} \mathrm{O}\right)$ using a glass lid that was sealed to the substrate with a UV-curable epoxy bead applied around its periphery. A $\mathrm{BaO}_{\mathrm{x}} / \mathrm{SrO}_{\mathrm{x}}$ desiccant was included within the package to remove residual $\mathrm{O}_{2}$ and $\mathrm{H}_{2} \mathrm{O}$. Performance characteristics of the as-grown devices at $25^{\circ} \mathrm{C}$ were: short-circuit current, $J_{S C}=$ 
$12.1 \pm 1 \mathrm{~mA} / \mathrm{cm}^{2}$, open-circuit voltage, $V_{O C}=0.93 \pm 0.01$, fill factor, $F F=61 \pm 1 \%$, and $P C E=$ $6.6 \pm 0.6 \%$ under 1 sun, $\mathrm{AM} 1.5 \mathrm{G}$ illumination.

Diurnal, temperature, and light intensity dependent cell characterization was performed at Sede Boqer, Israel $\left(30^{\circ} 51^{\prime} \mathrm{N}, 34^{\circ} 46^{\prime} \mathrm{E}\right)$ in the Negev Desert. Diurnal measurements were performed on a fixed platform set at a $60^{\circ}$ angle with respect to the surface normal. Current density vs. voltage $(J-V)$ characteristics were measured hourly from 9:00 am to 4:00 pm along with the cell temperature and incident light intensity. Low intensity data before 9:00 am and after 4:00 pm were not recorded. Five such measurements were taken for each device at the beginning of each hour and were averaged to compensate for fluctuations in irradiance. Temperature was measured on the surface of the OPV using a thermocouple, while intensity was measured with a calibrated Si photodiode.

Light intensity dependent OPV performance was measured using a solar concentrator from 0.2-27 suns $\left(1 \mathrm{sun}=100 \mathrm{~mW} / \mathrm{cm}^{2}\right)$. Sunlight was focused into a $1 \mathrm{~mm}$ diameter quartz-core optical fiber, and coupled onto the OPV cell. ${ }^{22,23}$ Flux uniformity was achieved by placing a multimode, $3 \mathrm{~cm} \times 1 \mathrm{~cm} \times 1 \mathrm{~cm}$ quartz block between the cell and the fiber. The intensity was calibrated using a pyranometer, and varied using an iris on the collection aperture. Both temperature and intensity dependent data were acquired during clear-sky periods (solar noon \pm 2 hr), during which the spectrum was very near to AM1.5G. ${ }^{12}$

Temperature dependent $J-V$ characteristics were measured at $1-2^{\circ} \mathrm{C}$ intervals outdoors using an automated solar tracking platform. Temperature was varied using a thermoelectric cooler and resistive heater, while cell temperature was monitored with a substrate-mounted thermistor. The temperature dependent external quantum efficiency (EQE) was measured indoors with a lock-in amplifier. A Xe-arc light source was monochromated and chopped at 200 
$\mathrm{Hz}$ and focused onto the device. The source intensity was calibrated with a Si photodiode. Temperature was controlled using a hot plate and monitored using a thermocouple. Reflectance of the OPV cell was measured $6^{\circ}$ from normal incidence using illumination from a calibrated UV-visible spectrometer. The temperature was controlled using a resistive heater with a $\mathrm{Cu}$ heatspreader, and measured using a thermocouple.

\section{Results}

Figure 1 shows the solar irradiance, cell temperature, and diurnal dependences of the photovoltaic parameters measured on November 8, 2015. The solar irradiance (Fig. 1a) follows a cosine law dependence reaching its maximum at noon, while temperature (Fig. 1a) increased from 9:00 am to 1:00 pm, with a maximum of $38^{\circ} \mathrm{C}$. Responsivity (Fig. 1b) slightly increased, while $V_{O C}$ and $F F$ remained nearly constant. As a result, $P C E$ is time dependent, varying between $6.8 \pm 0.3 \%$ at 9:00 am to its peak value of $7.7 \pm 0.3 \%$ at $2: 00 \mathrm{pm}$.

Devices were characterized as a function of light intensity from 0.2 to 27 suns, with several $J-V$ curves shown in Fig. 2a. Photovoltaic characteristics vs. illumination intensity are shown in Figs. $2 b-2 d$. Here, $J_{S C}$ increases linearly with intensity below $\sim 20$ suns. Similarly, $V_{O C}$ increases as the logarithm of intensity before saturating above $\sim 5$ suns. Fits to the low intensity region ( $<5$ suns) are shown in Fig. $2 \mathrm{~b}$ and $2 \mathrm{c}$ to highlight the deviation in responsivity and $V_{O C}$ from their respective linear and logarithmic relationships with intensity. The $F F$ decreases from $63 \%$ at 0.2 suns to $33 \%$ at 27 suns. This trend dominates the light intensity dependence of $P C E$. The latter reaches a maximum below 1 sun, although the decrease in both $F F$ and $P C E$ in the range of $0.2-1$ suns is negligible $(<3 \%$ relative). 
Figure 3 shows the effect of cell temperature on OPV performance. Fourth quadrant $J-V$ characteristics were measured under one sun illumination, as shown in Fig. 3a, with several operating characteristics plotted in Fig. 3b-3d as a function of $T$. As we can see, responsivity $\left(J_{S C}\right.$ normalized to irradiance) increases with temperature with a slope of $9.1 \pm 1 \times 10^{-6}(\mathrm{~A} / \mathrm{W}) /{ }^{\circ} \mathrm{C}$. The $V_{O C}$ decreases at a rate of $-2.9 \pm 0.4 \mathrm{mV} /{ }^{\circ} \mathrm{C}$. From $15^{\circ} \mathrm{C}$ to $50^{\circ} \mathrm{C}, F F$ increases with temperature, with little additional decrease from $50^{\circ} \mathrm{C}$ to $100^{\circ} \mathrm{C}$. It then decreases as temperature is increased above $100^{\circ} \mathrm{C}$. Correspondingly, $P C E$ increases with a temperature coefficient $0.02 \% /{ }^{\circ} \mathrm{C}$, with a maximum at $40^{\circ} \mathrm{C}$ before decreasing at higher temperatures.

Figure 4a depicts the OPV EQE spectra measured indoors at various temperatures (from $30^{\circ} \mathrm{C}$ to $130^{\circ} \mathrm{C}$ ), respectively. To highlight differences between the spectra, we plot the ratio of $E Q E(T)$ to its value at $T=30^{\circ} \mathrm{C}$ in Fig. $4 \mathrm{~b}$. The $E Q E$ increases slightly with temperature, with larger increases near the edges of the absorption features at $\lambda=540 \mathrm{~nm}, 590 \mathrm{~nm}$, and $700 \mathrm{~nm}$. The longest wavelength corresponds to the DBP: $\mathrm{C}_{70}$ charge transfer (CT) state absorption. ${ }^{24}$

The calculated photocurrent density, $J_{S C}^{\text {calc }}$, is the integral over $\lambda$ of the product of the measured spectral $E Q E$ and the number of incident photons, $N_{p}$, at each wavelength:

$$
J_{S C}^{\text {calc }}=q E Q E() N_{p}() d .
$$

where $q$ is the electron charge. Over the standard AM1.5G solar spectrum, $J_{S C}^{\text {calc }}$ increases from $12.1 \pm 0.3 \mathrm{~mA} / \mathrm{cm}^{2}$ at $30^{\circ} \mathrm{C}$ to $12.7 \pm 0.3 \mathrm{~mA} / \mathrm{cm}^{2}$ at $130^{\circ} \mathrm{C}$.

To determine the role of temperature dependent absorption on $E Q E(T)$, the OPV cell reflectance was measured from $25^{\circ} \mathrm{C}$ to $125^{\circ} \mathrm{C}$. Decreases in reflectance (corresponding to increases in absorbance) with temperature are observed at wavelengths where the $E Q E$ increases 
at $\lambda=540 \mathrm{~nm}, 590 \mathrm{~nm}, 700 \mathrm{~nm}$, and $>800 \mathrm{~nm}$. To highlight these temperature dependent changes, reflectance difference spectra $(\Delta R)$ were obtained by subtracting the room temperature reflectance from each of the higher temperature spectra, as shown in Fig. 4c.

\section{Discussion}

Light intensity and temperature play a significant role in determining the performance of OPV cells, and vary throughout the day as shown in Fig. 1a. As expected, the irradiance and cell temperature have similar shapes, with maxima near midday. Despite this variation, we find that the photovoltaic parameters (responsivity, $V_{O C}, F F$, and $P C E$ ) do not change significantly, as shown in Figs. 1b and 1c. Near 1 sun intensity, the responsivity is linear with irradiance, $V_{O C}$ is logarithmic, and $F F$ decreases slightly. However, as the illumination intensity increases further, losses incurred due to the series resistance become significant in the $11.3 \mathrm{~mm}^{2} \mathrm{OPV}$ s studied here. ${ }^{15,18,25}$ This results in a decrease in $F F$, as shown in Fig. 2d. Responsivity is also reduced at high irradiance (>20 suns) as evidenced by the nonlinearity in Fig. $2 b$ due to recombination and the resulting resistive voltage drop. ${ }^{18}$ To realize large area OPVs capable of operating above 1 sun, low resistance contacts such as metal grids are essential ${ }^{25,26}$.

Based on optical simulations, ${ }^{27}$ approximately $30 \%$ of the total incident solar power is absorbed by the OPV active layers in addition to a small percentage absorbed by the contacts, transport layers, and substrate. At 27 suns intensity, approximately $800 \mathrm{~W} / \mathrm{m}^{2}$ is converted to electrical power, depending on the current-voltage operating point. The remaining absorbed power of $>7 \mathrm{~kW} / \mathrm{m}^{2}$ is dissipated as heat through relaxation of high energy excitations, Joule heating, and absorption in the infrared. ${ }^{14}$ Now the open-circuit voltage $\left(V_{O C}\right)$ of the OPV is given by: 


$$
q V_{O C}=E_{\text {Hомо }, \text { Acceptor }}-E_{L U M O, \text { Donor }}-E_{B}-n k_{B} T \ln \left(A k_{\text {rec }} / J_{S C}\right),
$$

where $E_{\text {НОМO,Acceptor }}$ and $E_{L U M O, D o n o r}$ are the energies of the acceptor highest occupied molecular orbital (HOMO) and the donor lowest unoccupied molecular orbital (LUMO), $E_{B}$ is the binding energy of the polaron pair at the $\mathrm{HJ}, n$ is the diode ideality factor, $k_{B}$ is Boltzmann's constant, and $k_{r e c}$ is the free carrier bimolecular recombination coefficient. ${ }^{16}$ The coefficient, $A$, depends on several factors including the polaron pair recombination and dissociation rates, and the photocurrent. Using this expression, we can conclude that above 5 suns intensity, the deviation in $V_{O C}$ in Fig. 2c from the expected logarithmic relationship with intensity (which is proportional to $\left.J_{S C}\right)$ in Eq. 2 is a result of increased recombination due to heating. ${ }^{16,28}$ The linear decrease of $V_{O C}$ with $T$ (Fig. 3c) is also consistent with Eq. 2.

The increase in $F F$ (Fig. 3d) from $15^{\circ} \mathrm{C}$ to $50^{\circ} \mathrm{C}$ is a result of increased conductivity, and hence reduced series resistance $\left(R_{S}\right)$ in the organic semiconductor layers with temperature $\left(R_{S}\right.$ $=1.05 \pm 0.04 \Omega$ at $T=15^{\circ} \mathrm{C}, R_{S}=0.73 \pm 0.04 \Omega$ at $T=50^{\circ} \mathrm{C}$ ). However, as this contribution becomes small compared to the contact resistances at elevated temperatures $\left(R_{S}=0.71 \pm 0.03 \Omega\right.$ at $\left.T=140^{\circ} \mathrm{C}\right)$, its impact on $F F$ also is reduced. ${ }^{18,25,29}$ Additionally, the $F F$ is reduced by increased charge recombination and the changing ratio of maximum power point voltage to $V_{O C}$ due to decreasing $V_{O C}$ with temperature. Competition between these factors results in the lack of temperature dependence of $F F$ at $T>50^{\circ} \mathrm{C}$, and then its decrease above $100^{\circ} \mathrm{C}$.

The EQE of an OPV cell is the product of the absorption, exciton diffusion to the HJ, charge transfer (CT) state dissociation, and charge extraction efficiencies - each of which may depend on temperature. ${ }^{27}$ To our knowledge, there are no reports showing the temperature dependence of the $E Q E$ for OPV cells, although increases in $J_{S C}$ with temperature have been 
shown for both polymer ${ }^{8,12,30}$ and small molecule ${ }^{31}$ cells. In polymer devices, this increase is attributed $^{12,30}$ to the thermally activated hopping mobility of charge carriers ${ }^{32,33}$. Figures $4 \mathrm{a}$ and $4 \mathrm{~b}$ show that the temperature dependent current increase is wavelength dependent, suggesting that charge generation is responsible for this characteristic. Indeed, Fig. 4c indicates that the layer reflectance decreases with temperature (corresponding to an increase in absorbance) at the same wavelengths where increases in $E Q E$ are observed. Integrating the temperature dependent $E Q E$ over the AM1.5G solar spectrum, the increase in $J_{S C}^{\text {calc }}$ from $12.1 \pm 0.3 \mathrm{~mA} / \mathrm{cm}^{2}$ to $12.7 \pm 0.3$ $\mathrm{mA} / \mathrm{cm}^{2}$ between $T=25^{\circ} \mathrm{C}$ and $125^{\circ} \mathrm{C}$ accounts for most of the $8.5 \pm 3 \%$ relative increase in responsivity observed in Fig. 3b. Therefore, while increased mobility may be partially responsible for the increase in $J_{S C}$, we conclude that the increase is primarily due to the broadened optical absorption.

To understand the observed line shape changes in the EQE and in the absorption spectra, we consider the temperature dependence of phonon-electron coupling, which has been shown to result in the broadening and red-shift of absorption spectra in many optical materials. ${ }^{34-37}$ These shifts follow semi-empirical relationships based on a Bose-Einstein distribution of phonons, viz.: $34-37$

and

$$
\begin{aligned}
& \Gamma(T)=\Gamma_{0}\left(1+\frac{2}{e^{\Theta / T}-1}\right)+\Gamma_{1} \\
& E(T)=a-b\left(1+\frac{2}{e^{\Theta / T}-1}\right),
\end{aligned}
$$

where $\Gamma(T)$ is the spectral linewidth, $E(T)$ is the peak energy, $\Gamma_{l}$ is the absorption linewidth due to homogeneous broadening and configurational disorder, $T$ is temperature, $a$ is the peak position 
at $T=0 \mathrm{~K}, \Gamma_{0}$ and $b$ are constants related to the strength of electron-phonon coupling, and $\Theta$ is the average phonon temperature. ${ }^{34-37}$ Using a sum of Gaussians to fit the low energy edge of the EQE spectrum as shown in Fig. 5a, the full width at half maxima (FWHM) and peak energies can be extracted at each temperature. Plotting these line shape parameters for the Gaussians comprising the low energy tail vs. $T$, we find agreement with Eqs. 3 and 4, as shown in Fig. 5b, suggesting that the temperature broadened absorption spectra is the result of an increased phonon population at elevated temperatures.

Finally, we find that the diurnal dependence of OPV performance is a combination of the intensity and temperature dependent performance of the cells throughout the day. Comparing the temperature and intensity dependence of both $V_{O C}$ and $F F$, the trends nearly offset each other near 1 sun intensity, AM $1.5 \mathrm{G}$ illumination. That is, $F F$ increases with $T$ and decreases with intensity, while $V_{O C}$ increases with intensity and decreases with $T$. As a result, these characteristics remain nearly constant throughout the day. Responsivity, on the other hand, should not depend on light intensity at a constant quantum efficiency, as inferred from the linear dependence of $J_{S C}$ with irradiance. Responsivity appears to follow the change in temperature with a steady increase throughout the day, as shown in Fig. 1b. However, slight increases are observed at 2:00 and 3:00 pm, despite the decreasing temperature, leading to a $P C E$ maximum at 2:00pm. While small, this effect may be a result of solar spectral shifts as the sun approaches the horizon. ${ }^{38}$ Due to a combination of these several factors, $P C E$ follows responsivity by increasing from $6.8 \pm 0.1 \%$ at $9: 00$ am to $7.7 \pm 0.3 \%$ at $2: 00 \mathrm{pm}$.

\section{Conclusion}

The diurnal performance of small-molecule planar-mixed HJ DBP:C 70 OPV cells was measured outdoors, and found to be dependent on both temperature and light intensity. Under 
outdoor operation at intensities $\leq 1$ sun, $P C E$ remains within $3 \%$ of its maximum before falling off at high irradiance due to resistive losses that reduce $F F$. The $P C E$ is found to have a positive temperature coefficient $\left(0.02 \% /{ }^{\circ} \mathrm{C}\right)$ from $15^{\circ} \mathrm{C}$ to $40^{\circ} \mathrm{C}$ since the temperature dependent increases in $J_{S C}$ and $F F$ offset decreases in $V_{O C}$. Absorption spectral broadening is responsible for most of the increase in $J_{S C}$, consistent with enhanced phonon-electron coupling at elevated temperatures. This finding differs from previous reports that attribute the temperature dependence of $J_{S C}$ to temperature dependent increases in charge hopping mobility. Compared with inorganic photovoltaics whose efficiency decreases at elevated temperatures and often require optical concentrators to reach their maximum $P C E$, small molecule OPV cells are optimal for outdoor temperatures and light intensities, reaching their peak efficiency near $40^{\circ} \mathrm{C}$ and remaining within $3 \%$ of their maximum $P C E$ at 1 sun intensity.

\section{Acknowledgements}

The authors are grateful to Vladimir Melnichak for assistance in the design and operation

of experimental setups. This work was partially financially supported by the United States Department of Energy SunShot Program under Awards DE-EE0006708 and DE-EE0005310. Q.B. thanks the US-Israel Binational Science Foundation for providing a travel grant. E.A.K. thanks the Adelis Foundation. L.C. and G.Z. are thankful to the Ente Nazionale Energia e Ambiente and the Italian Ministry of Foreign Affairs for visitor post-doc fellowships to BenGurion University of the Negev. 


\section{References}

${ }^{1}$ S.B. Darling and F. You, RSC Adv. 3, 17633 (2013).

${ }^{2}$ J. Huang, C.Z. Li, C.C. Chueh, S.Q. Liu, J.S. Yu, and A.K.Y. Jen, Adv. Energy Mater. 5, 1500406 (2015).

${ }^{3}$ Q. Zhang, B. Kan, F. Liu, G. Long, X. Wan, X. Chen, Y. Zuo, W. Ni, H. Zhang, M. Li, Z. Hu, F. Huang, Y. Cao, Z. Liang, M. Zhang, T.P. Russell, and Y. Chen, Nat. Photonics 9, 35 (2014).

${ }^{4}$ C.C. Chen, W.H. Chang, K. Yoshimura, K. Ohya, J. You, J. Gao, Z. Hong, and Y. Yang, Adv. Mater. 26, 5670 (2014).

${ }^{5}$ Q. Burlingame, B. Song, L. Ciammaruchi, G. Zanotti, J. Hankett, Z. Chen, E.A. Katz, and S.R. Forrest, Adv. Energy Mater. 1601094 (2016).

${ }^{6}$ A.Q. Malik and S.J.B.H. Damit, Renew. Energy 28, 1433 (2003).

${ }^{7}$ R. Gottschalg, T.R. Betts, D.G. Infield, and M.J. Kearney, Sol. Energy Mater. Sol. Cells 85, 415 (2005).

${ }^{8}$ N. Bristow and J. Kettle, J. Renew. Sustain. Energy 7, 13111 (2015).

${ }^{9}$ M. Corazza, F.C. Krebs, and S.A. Gevorgyan, Sol. Energy Mater. Sol. Cells 143, 467 (2015).

${ }^{10}$ G. Lakhwani, A. Rao, and R.H. Friend, Annu. Rev. Phys. Chem. 65, 557 (2014).

${ }^{11}$ N.K. Elumalai and A. Uddin, Energy Environ. Sci. 9, 391 (2016).

${ }^{12}$ E.A. Katz, D. Faiman, S.M. Tuladhar, J.M. Kroon, M.M. Wienk, T. Fromherz, F. Padinger, C.J. Brabec, and N.S. Sariciftci, J. Appl. Phys. 90, 5343 (2001).

${ }^{13}$ D. Bartesaghi, I.D.C. Pérez, J. Kniepert, S. Roland, M. Turbiez, D. Neher, and L.J.A. Koster, 
Nat. Commun. 6, 7083 (2015).

${ }^{14}$ I. Visoly-Fisher, A. Mescheloff, M. Gabay, C. Bounioux, L. Zeiri, M. Sansotera, A.E.

Goryachev, A. Braun, Y. Galagan, and E.A. Katz, Sol. Energy Mater. Sol. Cells 134, 99 (2015).

${ }^{15}$ T. Tromholt, E.A. Katz, B. Hirsch, A. Vossier, and F.C. Krebs, Appl. Phys. Lett. 96, (2010).

${ }^{16}$ N.C. Giebink, G.P. Wiederrecht, M.R. Wasielewski, and S.R. Forrest, Phys. Rev. B 82, 155305 (2010).

${ }^{17}$ A.K. Thakur, G. Wantz, G. Garcia-Belmonte, J. Bisquert, and L. Hirsch, Sol. Energy Mater. Sol. Cells 95, 2131 (2011).

${ }^{18}$ A. Manor, E.A. Katz, T. Tromholt, B. Hirsch, and F.C. Krebs, J. Appl. Phys. 109, 74508 (2011).

${ }^{19}$ X. Xiao, K.J. Bergemann, J.D. Zimmerman, K. Lee, and S.R. Forrest, Adv. Energy Mater. 4, 1301557 (2014).

${ }^{20}$ A.R. McGhie, A.F. Garito, and A.J. Heeger, J. Cryst. Growth 22, 295 (1974).

${ }^{21}$ N. Wang, J.D. Zimmerman, X. Tong, X. Xiao, J. Yu, and S.R. Forrest, Appl. Phys. Lett. 101, 133901 (2012).

${ }^{22}$ J.M. Gordon, E.A. Katz, D. Feuermann, and M. Huleihil, Appl. Phys. Lett. 84, 3642 (2004).

${ }^{23}$ E.A. Katz, J.M. Gordon, W. Tassew, and D. Feuermann, J. Appl. Phys. 100, 44514 (2006).

${ }^{24}$ X. Liu, K. Ding, A. Panda, and S.R. Forrest, ACS Nano 10, 7619 (2016).

${ }^{25}$ X. Xiao, K. Lee, and S.R. Forrest, Appl. Phys. Lett. 106, 213301 (2015).

${ }^{26}$ S.Y. Park, W.I. Jeong, D.G. Kim, J.K. Kim, D.C. Lim, J.H. Kim, J.J. Kim, and J.W. Kang, 
Appl. Phys. Lett. 96, (2010).

${ }^{27}$ P. Peumans, A. Yakimov, and S.R. Forrest, J. Appl. Phys. 93, 3693 (2003).

${ }^{28}$ L.J.A. Koster, V.D. Mihailetchi, R. Ramaker, and P.W.M. Blom, Appl. Phys. Lett. 86, 123509 (2005).

${ }^{29}$ J.D. Servaites, S. Yeganeh, T.J. Marks, and M.A. Ratner, Adv. Funct. Mater. 20, 97 (2010).

${ }^{30}$ I. Riedel, J. Parisi, V. Dyakonov, L. Lutsen, D. Vanderzande, and J.C.C. Hummelen, Adv. Funct. Mater. 14, 38 (2004).

${ }^{31}$ U. Hörmann, J. Kraus, M. Gruber, C. Schuhmair, T. Linderl, S. Grob, S. Kapfinger, K. Klein, M. Stutzman, H.J. Krenner, and W. Brütting, Phys. Rev. B - Condens. Matter Mater. Phys. 88, 235307 (2013).

${ }^{32}$ H. Bässler, Phys. Status Solidi B 175, 15 (1993).

${ }^{33}$ V.D. Mihailetchi, J.K.J. Van Duren, P.W.M. Blom, J.C. Hummelen, R.A.J. Janssen, J.M.

Kroon, M.T. Rispens, W.J.H. Verhees, and M.M. Wienk, Adv. Funct. Mater. 13, 43 (2003).

${ }^{34}$ K. Huang and A. Rhys, Proc. R. Soc. London Ser. a-Mathematical Phys. Sci. 204, 406 (1950).

${ }^{35}$ P. Lautenschlager, M. Garriga, S. Logothetidis, and M. Cardona, Phys. Rev. B 35, 9174 (1987).

${ }^{36}$ L. Vina, S. Logothetidis, and M. Cardona, Phys. Rev. B 30, 1979 (1984).

${ }^{37}$ K.P. O’Donnell and X. Chen, Appl. Phys. Lett. 58, 2924 (1991).

${ }^{38}$ K.W. Böer, Sol. Energy 19, 525 (1977). 


\section{Figure Captions}

Figure 1 (a) Irradiance, outdoor cell temperature, (b) responsivity, $V_{O C}$, (c) $F F$, and $P C E$ vs. the time of day on November 8, 2015 in Sede Boqer, Israel for a DBP:C 70 planar-mixed heterojunction organic solar cell.

Figure 2 (a) Current density vs. voltage characteristics at 0.2 sun, 1 sun, 3.5 sun, 13 sun, and 27 sun illumination intensity for the cell in Fig. 1. (b) Short circuit current density, $J_{S C},(\mathbf{c}) V_{O C},(\mathbf{d})$ $F F$ (left axis) and $P C E$ (right axis) vs. irradiance.

Figure 3 (a) Current density vs. voltage characteristics under 1 sun intensity at various temperatures. (b) Responsivity, (c) open-circuit voltage $\left(V_{O C}\right)$, (d) fill factor $(F F)$ and power conversion efficiency $(P C E)$ as functions of temperature from $15^{\circ} \mathrm{C}$ to $140^{\circ} \mathrm{C}$.

Figure 4 (a) External quantum efficiency $(E Q E)$ and (b) and ratio $E Q E(T) / E Q E\left(30^{\circ} \mathrm{C}\right)$ as functions of wavelength and temperature. (c) Difference in reflectance $(\Delta R)$ between temperature, $T$, and $T=25^{\circ} \mathrm{C}$ vs. wavelength from $50^{\circ} \mathrm{C}$ to $125^{\circ} \mathrm{C}$.

Figure 5 (a) $E Q E$ vs. energy at $30^{\circ} \mathrm{C}$ with a fit to two Gaussians shown. (b) Normalized Gaussian fit parameters vs. $T$. 


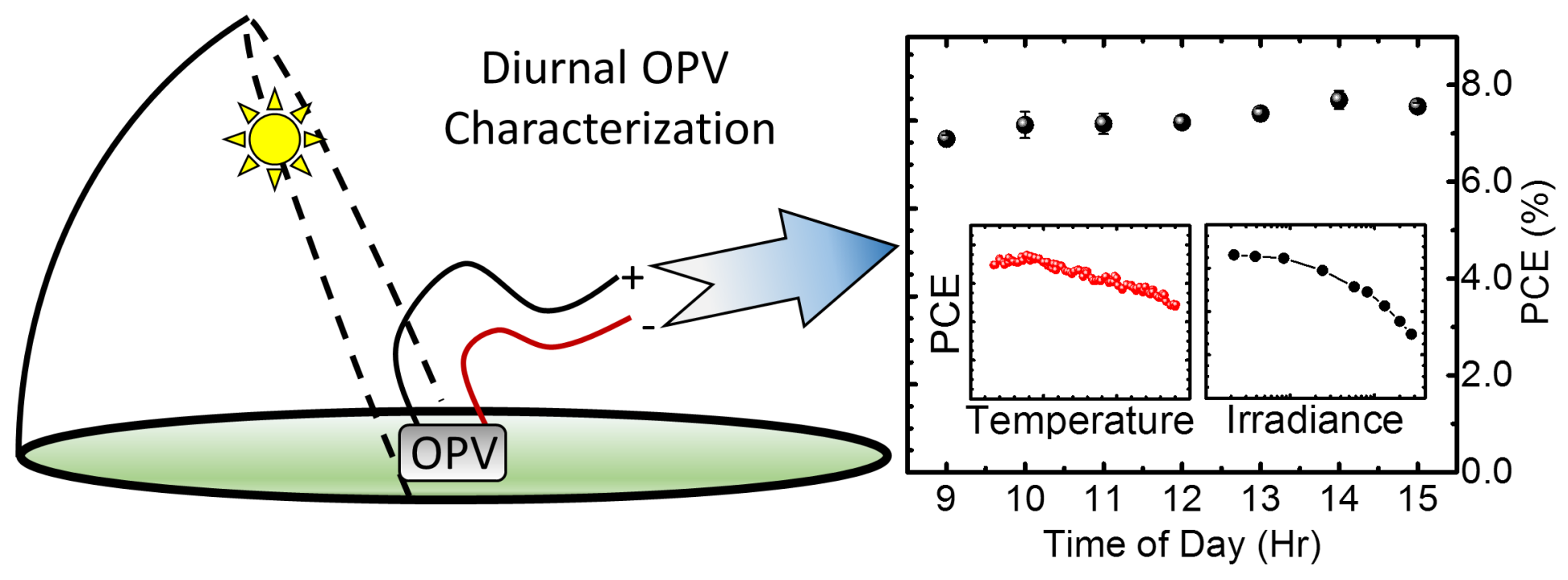


Fig. 1

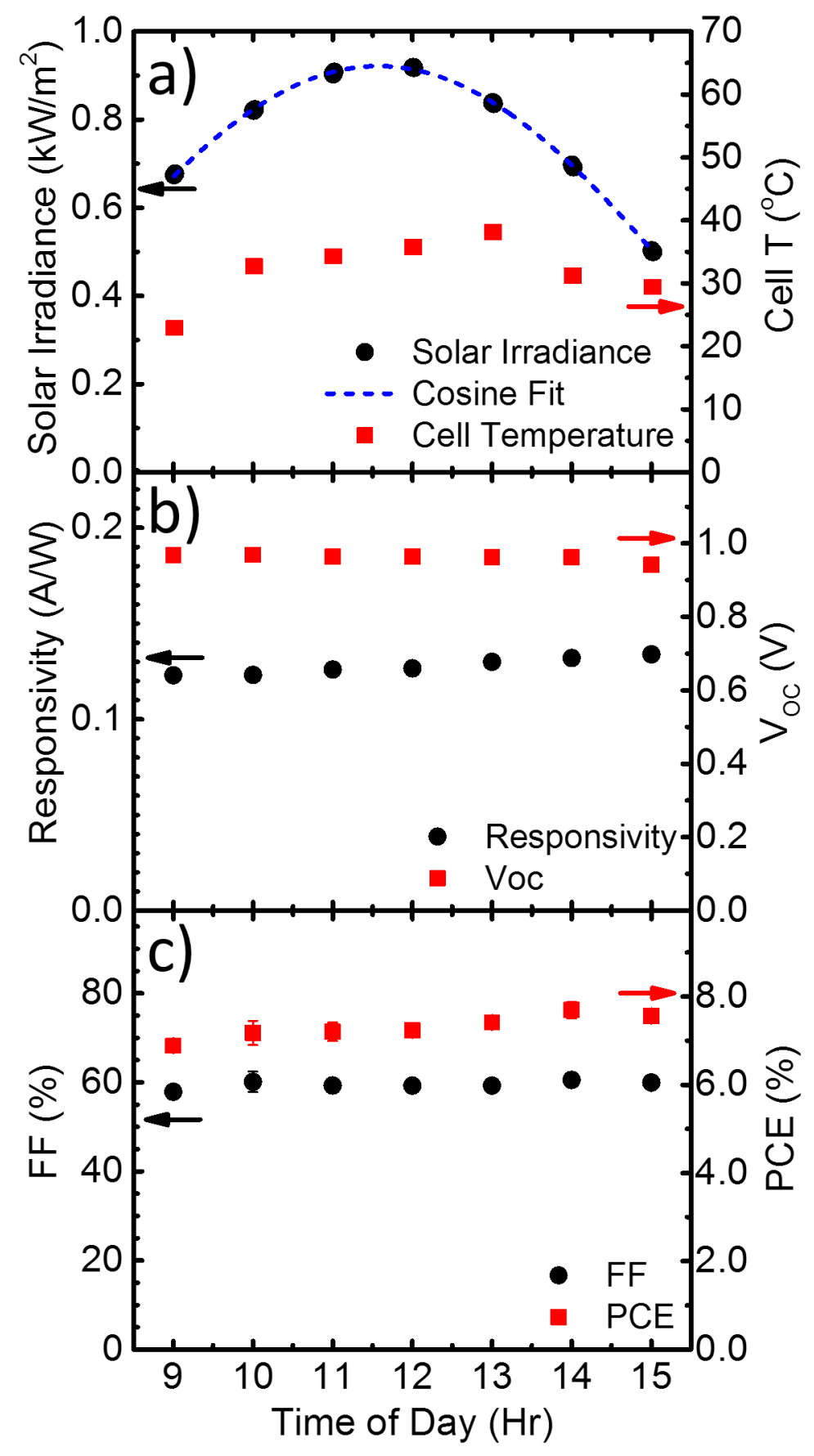


Fig. 2
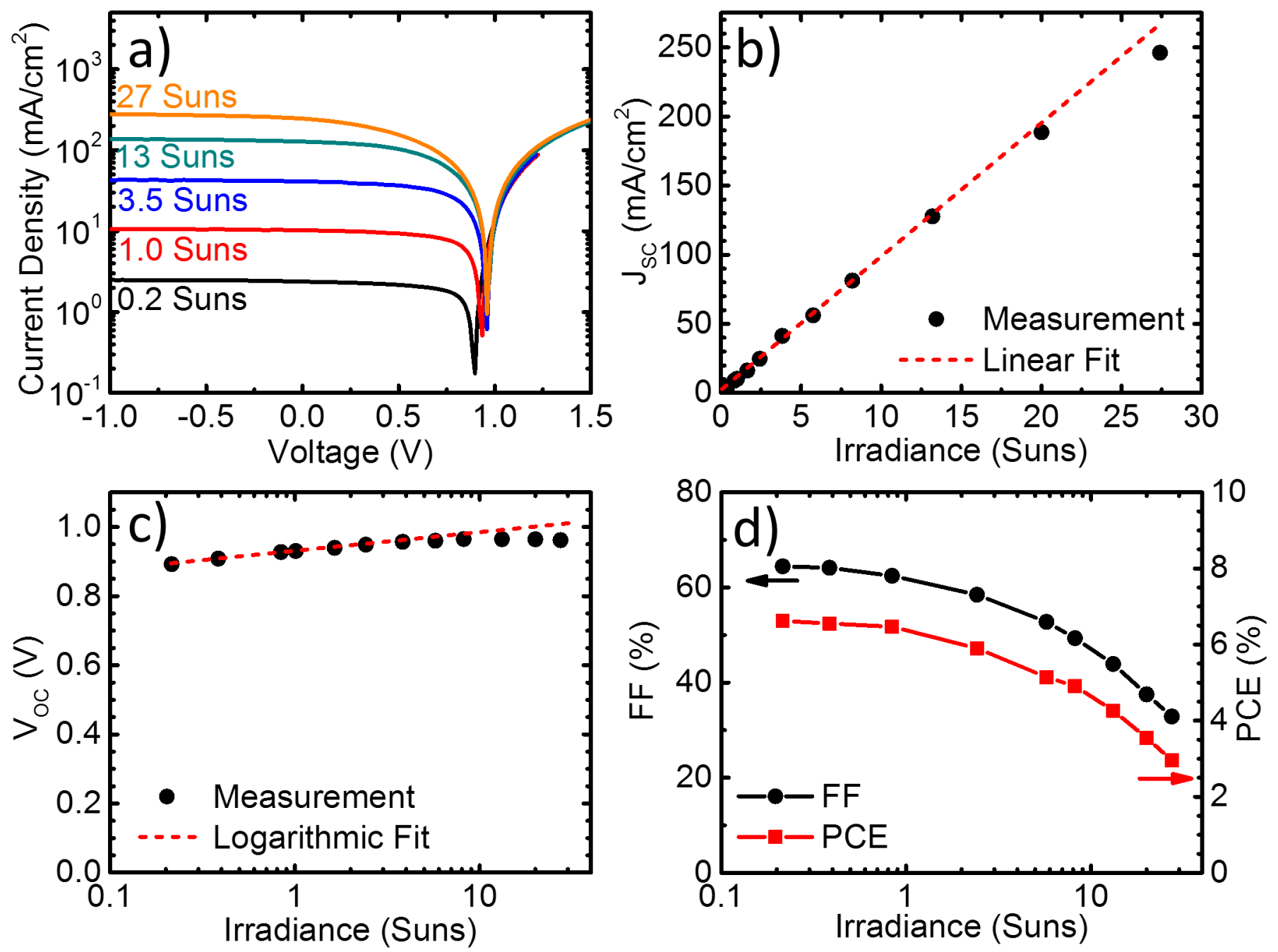
Fig. 3
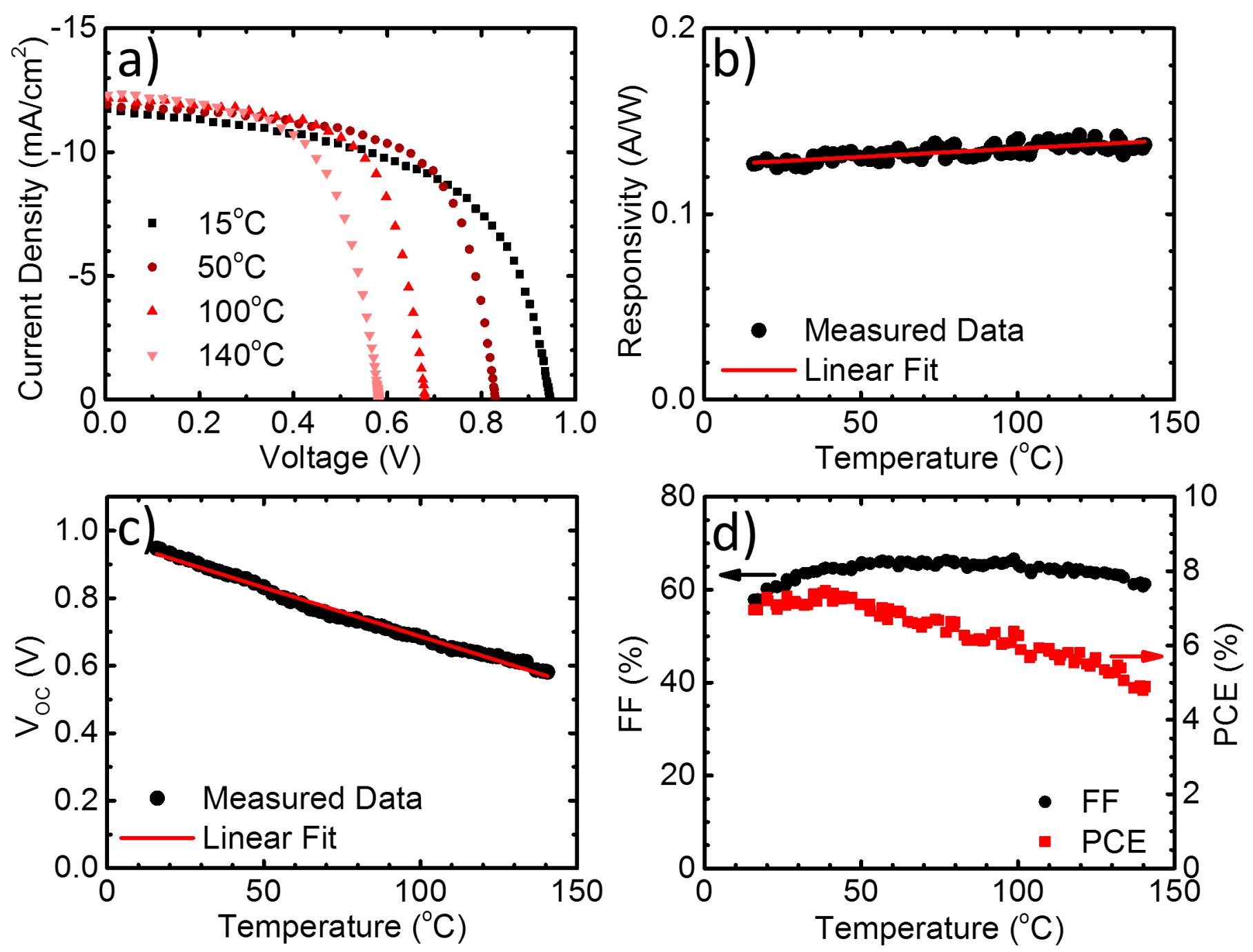


\section{Fig. 4}

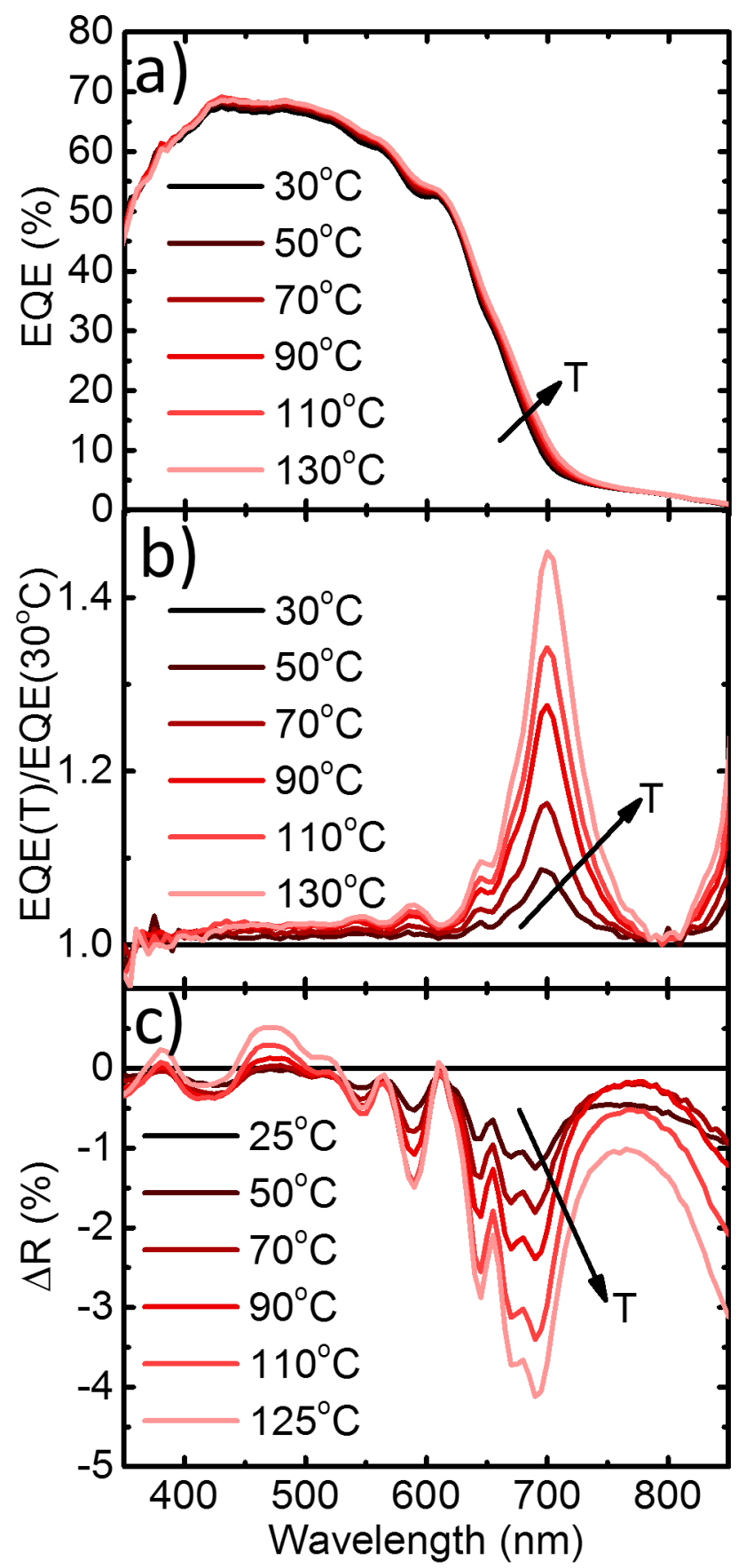




\section{Fig. 5}
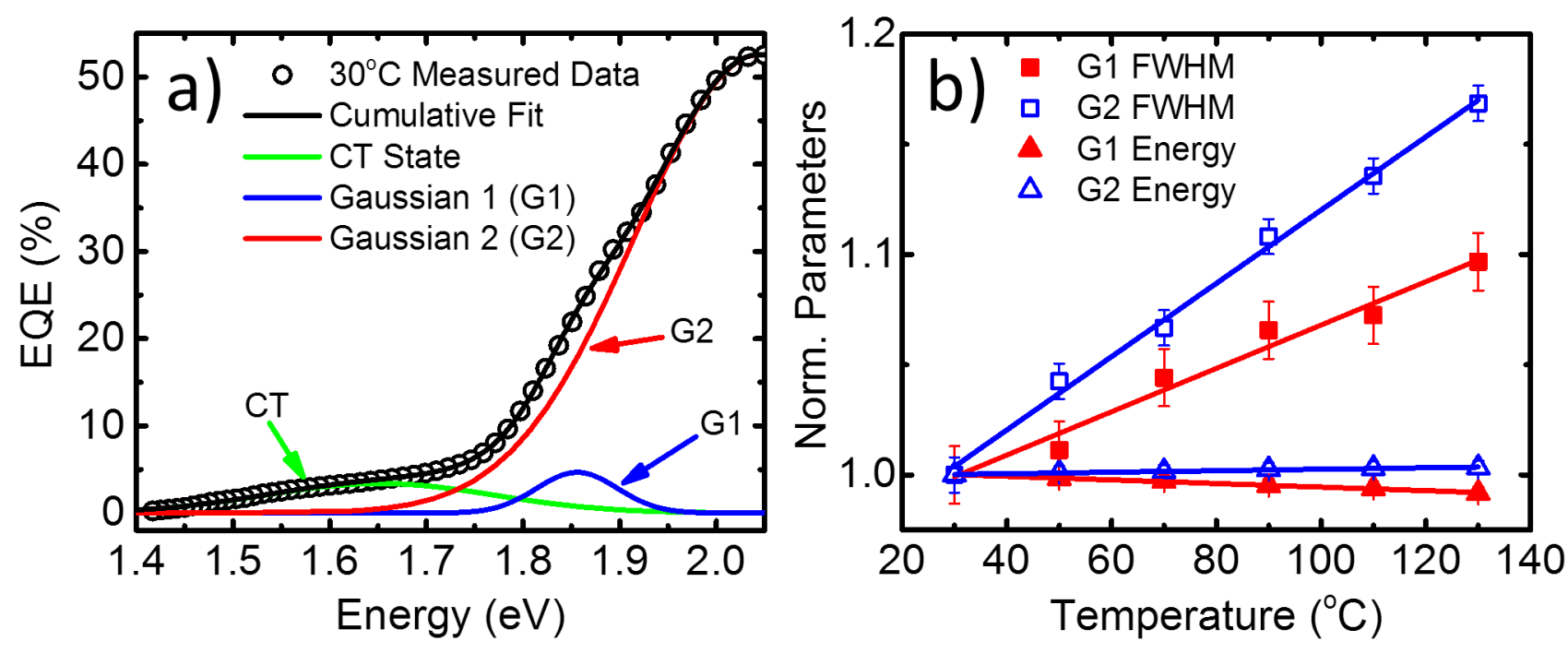